\title{
As tecnologias de informação e comunicação (TIC) no ensino de literatura: uma perspectiva pós-moderna
}

\author{
Aldenora Márcia C. Pinheiro CARVALHO* \\ Reinaldo Portal DOMINGO**
}

\begin{abstract}
Resumo: Este artigo analisa os prováveis modelos de inserção de tecnologias de informação e comunicação para o ensino de literatura no âmbito da modernidade tardia. Embasado nos pressupostos teóricos dos estudos pós-modernos e na crítica às teorias sociais do currículo, pretende-se ainda, com este estudo, considerar as principais acepções acerca de conceitos como tecnologia de informação e comunicação, ensino de literatura e teorias do currículo enquanto elementos construtores de uma formação moderna, integral e abrangente. Para tanto, tomaremos por base os instrumentos teóricos trabalhados por Demo (2009), Bhabha (2010), Goodson (2007), Silva (1999) e, no campo literário, Colomer (2010).
\end{abstract}

Palavras-chave: Tecnologias. Literatura. Ensino-aprendizagem. Pós-modernidade.

Abstract: This paper analyzes the probable insertion models of information technologies and communication when the teaching of literature in the field of late modernity. Grounded in theoretical studies of postmodern and critical theories of social curriculum is intended with this study to consider the main meanings about concepts such as information technology and communication, teaching Literature and theories of curriculum as part of a training builders modern, integrated and comprehensive. To do so, we will build on the theoretical tools worked by Demo (2009), Bhabha (2010), Goodson (2007), Silva (1999) and, in the literary field, Colomer (2010).

Keywords: Technology. Literature. Teaching and learning. Post-modernity.

\section{Introdução: sobre o currículo e a modernidade}

A expressão curriculum tal como é empregada usualmente nos países europeus se deu pela influência da literatura educacional americana e, inicialmente, designava um campo especializado de estudos. Assim, possivelmente as condições associadas à institucionalização da educação massiva permitiram que essa área de estudos se tornasse um campo profissional especializado. Tomaz Silva (1999) afirma que a existência de teorias sobre o currículo está intimamente relacionada a uma espécie de emergência de o "campo do currículo" ser identificado como "campo de pesquisa".

Nesse sentido, Bobbitt (1918) em The Curriculum propunha que a escola passasse a funcionar nos mesmos moldes de qualquer empreendimento mercantilista ou industrial. Nessa perspectiva, o currículo funcionava como uma mecânica, isto é, o

\footnotetext{
"Mestranda do Programa de Pós-Graduação Mestrado Interdisciplinar Cultura e Sociedade - UFMA. Professora substituta do Departamento de Letras da Universidade Federal do Maranhão - UFMA. herabello@hotmail.com.

** Professor Doutor em Tecnologia Educativa - Academia de Educação da Rússia. Professor titular e coordenador Pedagógico do Núcleo de Educação à Distância NEAD-UFMA e Coordenador Adjunto da UAB-UFMA. reynaldoportal@ufma.br
} 
sistema educacional definiria seus objetivos baseados no atendimento das habilidades que a sociedade necessitasse quando se tratava da formação das massas para o trabalho. O modelo proposto por Bobbitt encontrou em Tyler (1949) sua estabilização definitiva trinta e um anos depois; porém, tal modelo inseria, com novas acepções, a inclusão de fontes que não tinham sido contempladas por Bobbitt, tais como a psicologia e as disciplinas acadêmicas. Nesse caso, a inclusão das competências tecnológicas no currículo, que são oriundas da modernidade tardia, estaria contemplada nesse espaço.

A partir dessas afirmações, e por se tratar de um conceito relativamente complexo e recente, podemos considerar o currículo conforme aponta Sacristán (2000), não como um conceito, mas, como uma construção cultural, isto é, como um modo de organização das práticas educativas. Práticas estas que estão atreladas a um esquema organizacional que pretende disciplinar, ampliar e desenvolver a educação. Desse modo, discutiremos a noção de currículo baseados em uma concepção de que ele é o resultado de um conceito essencial para compreender as práticas educativas. Em síntese, "o currículo supõe a concretização dos fins sociais e culturais, de socialização, que se atribui à educação escolarizada. [...] Relaciona-se com a instrumentalização concreta que faz da escola um sistema social”. (SACRISTÁN, op. cit. p.15)

Quando escreve sobre os estudos culturais e o currículo na obra Documentos de Identidade: uma introdução às teorias do currículo, Tomaz Tadeu da Silva (1999) descreve o campo de teorização e investigação conhecido como Estudos Culturais que teve como principal questionamento a compreensão sobre a cultura dominante na crítica literária. Nesse sentido, os Estudos Culturais permitiriam idealizar o currículo como uma esfera de luta em torno da significação e da identidade, isto é, a partir dos Estudos Culturais, "podemos ver o conhecimento e o currículo como campos culturais, como campos sujeitos à disputa e à interpretação, nos quais os diferentes grupos tentam estabelecer sua hegemonia" (SILVA, op. cit. p. 134). Dessa forma, e infundida nos Estudos Culturais, seria possível uma equiparação das diversas formas de conhecimento.

Porém, qualquer tentativa de conclusão sobre as questões referentes ao currículo suscitam inúmeras ideias e estas estarão sempre associadas às distintas concepções, das quais decorre a variedade de formas pelas quais a educação é concebida historicamente. Uma alternativa proposta por Goodson (2007) aponta que, "no novo futuro social, devemos esperar que o currículo prescritivo se comprometa com as 
missões, paixões, e propósitos que as pessoas articulam em suas vidas" (GOODSON, 2007, p. 251). E acrescenta ainda:

Grande parte da literatura sobre aprendizagem falha na abordagem dessa questão crucial do interesse, por isso a aprendizagem é vista como uma tarefa formal que não se relaciona com as necessidades e interesses dos alunos, uma vez que muito do planejamento curricular se baseia nas definições prescritivas sobre o que se deve aprender, sem nenhuma compreensão da situação de vida dos alunos. Como resultado, um grande número de planejamentos curriculares fracassa, porque o aluno simplesmente não se sente atraído ou engajado. (GOODSON, 2007, p. 250)

Observa-se que, invariavelmente as atividades de leitura executadas durante as aulas de literatura, precisam antes de tudo, atender uma demanda gerada pelo currículo formal que prescreve um conjunto de diretrizes que servem para organizar as práticas pedagógicas em torno da leitura literária. A partir dessa imbricação, todas as crises do currículo e por extensão da educação, deixam de ser um problema interno e exclusivo da escola e tornam-se uma questão de concepção.

Como exemplo disso, Goodson (op. cit.) assinala para a ideia de uma nova crise na modernidade e corrobora, nesse sentido, quando afirma que esse sentimento indiscutível de crises que está sendo experimentado por teóricos, pesquisadores, filósofos e profissionais da área da educação não tem relação apenas com as ausências, os equívocos ou as inadequações do profissional da área da pedagogia. Nesse sentido, esse sentimento quase universal de impotência diante dessas crises ou ainda diante dos atuais teorias sobre a educação, tem relação direta com a identificação de uma espécie de "fusão universal das identidades - processos de formação, a dispersão de autoridades, a polifonia das mensagens e a consequente fragmentação da vida que caracterizam o mundo em que vivemos". (GOODSON, op. cit. p. 242). A partir desse entendimento, podemos identificar que a ênfase nesse sentido não pretende privilegiar a escola na defesa de uma instituição exata e sem falhas.

Por essa razão, podemos inferir a ideia das tecnologias de informação e comunicação na área do ensino de literatura no processo de aquisição desses conhecimentos que estão legitimados pelo currículo. Nessa esfera, os aparatos conceituais e metodológicos passam a ser observados a partir da prescrição curricular e, não obstante a autonomia assumida pelas diversas áreas do saber, a inserção das 
tecnologias de comunicação deverão, a exemplo das demais áreas, vincular-se a uma organização curricular.

Ampliando a discussão para o conceito de modernidade, podemos compreender que tal ideia deriva de um conjunto de concepções acerca de novos padrões de comportamento e pensamento do homem na atualidade. Assim, na modernidade tardia seria os homens se deslocam com relativa facilidade em direção a outros espaços de conhecimento e descobertas. Observa-se, porém, que determinados códigos humanos precisam ser categoricamente absorvidos quando da entrada na cultura do outro. Nesse esquema relacional, a completa compreensão dos códigos da linguagem tecnológica adquire um novo paradigma para as ciências humanas e sociais e torna-se uma nova categoria de análise quando das pesquisas científicas para a atualidade.

A partir dessa ideia, a linguagem é, pois, um dos principais elementos de identificação desse processo, isto é, na modernidade, o acesso ou o não-acesso aos códigos da linguagem é o primeiro elemento a desterritorializar o sujeito. Nessa perspectiva, podemos citar o exemplo daquele indivíduo estrangeiro que, num processo de relação social é considerado um sujeito desterritorializado, pois não compreende, nem reconhece a linguagem do outro e, por isso, não será capaz de completar o processo de comunicação por meio da língua que é utilizada em sua volta.

Da mesma forma, o acesso aos códigos tecnológicos pressupõe uma adequação à realidade imediata que se apresenta ao homem moderno. Portanto, a tentativa de inserção das tecnologias de comunicação e informação ao sujeito que recusa tais ideias em torno da modernidade é fracassada e não passa de ideologia do discurso moderno para inclusão desse homem no padrão da modernidade tardia. Por essa razão, observaremos a ideia em torno da ideologia no uso das TIC.

\section{Da ideologia ao uso de TIC: onde a crítica começa.}

O pensamento e a estrutura educacional de caráter tradicional foram amplamente questionados na década de 60. Assim, Althusser, Bourdieu, Passeron, Baudelot e Establet produziram diversas renovações nas teorias educacionais que modificariam consecutivamente a teoria educacional tradicional. Assim, as novas teorias críticas eram "teorias de desconfiança, questionamento e transformação radical", 
isto é, se opunham às teorias tradicionais que mantinham um caráter de "aceitação, ajuste e adaptação" (SILVA, 1999, p. 142).

Dentre os conceitos trabalhados nessa nova abordagem está o ensaio de Althusser A ideologia e os aparelhos ideológicos de Estado que forneceria mais tarde as bases para as críticas marxistas da educação. Assim, para Althusser, a permanência da sociedade capitalista se sustentaria por haver mecanismos ou instituições que seriam encarregadas de garantir seu estado atual, isto é, os aparelhos repressivos de estado - a polícia e o judiciário - por meio da força; e os aparelhos ideológicos de estado - a religião, a mídia, a escola e a família - por meio do convencimento, da repressão e da ideologia; garantiria que a sociedade capitalista se mantivesse tal como está.

Nesse sentido, a escola se constituiria num aparelho ideológico central, "porque atinge praticamente toda a população por um período prolongado de tempo" (op. cit. p. 142) e, assim, a escola atua ideologicamente por meio de seu currículo. Os ensaios de Althusser e ainda, as contribuições teóricas de Baudelot e Establet, bem como os pressupostos trabalhados por Bowles e Gintis formaram a base da teoria educacional crítica que vieram a se desenvolver posteriormente e, mesmo sofrendo críticas, as teorizações mais recentes sobre o currículo, ainda se sustentam com base nessas ideias mencionadas.

Não obstante a diversidade crítica a respeito do sistema educacional é possível observar que existem teorias que foram reformuladas para receber novas designações no campo da educação. Nesse aspecto, a escola enquanto instituição social buscou atuar numa configuração atualizada e aderiu às expectativas de uma sociedade moderna e informatizada e inseriu nos programas curriculares as TIC. A exemplo disso podemos citar o componente curricular informática que recebia essa designação até o final da década de 90 e início dos anos 2000, quando foram inseridos novos conceitos sobre as tecnologias de comunicação no mundo moderno.

É possível elencar ainda a observação necessária para o percurso e para as reflexões acerca das novas abordagens que ganhou um enfoque mais conciso no final do século XX e acompanhou também, a evidente mudança de comportamento do sujeito leitor. Por essa razão, o sujeito leitor que se colocou como objeto de investigação para a Literatura e as tecnologias de informação e comunicação, passou a ser observado em primeiro plano, posto que foi esse sujeito quem concretizou os possíveis sistemas de realização dessas novas informações. Conforme destaca Almeida (2012): 
Um fator importante na mudança do horizonte de expectativas dos leitores que passaram da leitura dos folhetins à leitura das narrativas de gênero, notadamente a literatura policial, foi a ampliação da circulação de informação acerca da ciência que ocorreu no século XIX. A familiaridade crescente com o repertório científico e o tipo de raciocínio que este demandava foram decisivos para os desdobramentos desse e de outros gêneros - também poderíamos mencionar a ficção científica, sem dúvida, e o romance de aventuras. (ALMEIDA, 2012, p. 107)

Observamos que segundo as ideias do autor, a segunda metade do século XIX marcou de forma definitiva a maneira de fazer ciência e, inevitavelmente, a imagem das novas abordagens sobre as descobertas das ciências tiveram grande impacto sobre os leitores. Ou seja, as descobertas nos diversos campos dos saberes fez surgir uma notável confiança nos novos achados e, graças a essa segurança, tais novidades puderam se consolidar ao longo do século XX.

A exemplo dessa nova configuração, no final do século passado e, por quase uma década pensou-se a informática enquanto elemento curricular com fins quase exclusivos à instrumentalização do sujeito objetivando à sua formação para o mercado de trabalho que se tornava cada vez mais competitivo e globalizado. Com o passar do tempo e o surgimento de novas concepções acerca da linguagem tecnológica e seu uso, as instituições educacionais, principalmente as escolas de educação básica, perceberam que a formação em informática de base, convencionada ao currículo, prescindia da escola. Dentro dessa organização, a informática perdeu espaço no currículo prescritivo e foi suplantada como matéria a ser ensinada a escola.

Excetuando-se nessa configuração, os cursos em tecnologias da informação vinculados à formação profissional que são oferecidos pelas instituições de ensino superior; aquela ultrapassada concepção de ensino aprendizagem de informática na escola básica esgarçou-se tão rapidamente quanto a sucessão de novos softwares para o aperfeiçoamento dos novos dispositivos tecnológicos desenvolvidos na modernidade tardia. Se pensarmos em outros processos observados pela ciência nas últimas décadas, constataremos que a adequação aos novos códigos de uso das tecnologias de informação e comunicação foi, sem dúvida, bastante célere.

Por essa razão, a tentativa de inserir os campos do conhecimento tecnológico como base para o ensino de Literatura, passa necessariamente pelo currículo. Essas diretrizes, na verdade, representam uma possibilidade de legitimação daquilo que as propostas curriculares poderiam ou deveriam impor. Obviamente, cada proposta 
curricular apresenta em sua essência uma equivalência discursiva à prática pedagógica de determinada demanda escolar atrelada às demandas da sociedade.

\section{A literatura e a ideologia}

Chegamos assim a uma dimensão onde é possível compreendermos que a Literatura permaneceu durante muito tempo num plano supostamente superior em relação às demais funções da escola. Porém, isso não significa dizer que a Literatura estaria desprovida de um discurso ideológico, pelo contrário, concebida enquanto elemento formador de cultura haveria por detrás do sistema de ideias que sustentam a Literatura, um discurso de padrão ideológico também. Para efeito de esclarecimento, nessa acepção, e uma vez concebida enquanto arte, existiria na Literatura, uma ideologia. Conforme Terry Eagleton (2011), a discussão estaria na relação entre a arte e a ideologia.

Toda arte surge de uma concepção ideológica do mundo; não existe [...] qualquer obra de arte que seja inteiramente livre de conteúdo ideológico. [...] A literatura não é nada mais que a ideologia em uma determinada forma artística - as obras literárias são apenas uma forma de expressão das ideologias da época. Elas são prisioneiras da falsa consciência, incapazes de superá-la para encontrar a verdade. (EAGLETON, 2011, p. 37)

Observamos, segundo essa concepção, que o autor esclarece sobre um posicionamento característico da crítica marxista de concepção nitidamente comum que insiste em ver a obra literária como um mero reflexo das ideologias dominantes. Porém, tal como explica Eagleton, essa crítica vulgar seria incapaz de elucidar essa relação, porque, conforme se observou ao longo dos séculos, "as obras de arte desafiaram os pressupostos ideológicos de sua época. [...] a arte não pode ser reduzida à ideologia: há, em vez disso, uma relação entre elas". (op. cit. p. 38). Deriva desse argumento a premissa de que as ideologias representam esse sistema de ideais com as quais o homem vive e configura o mundo ao seu redor.

Assim, podemos inferir que a Literatura é, sem dúvida, um componente curricular propício para a inferência de ideologias, para além de despertar diversas experiências estéticas. Isso explica a permanência de temáticas vinculadas à Literatura concebida enquanto alta cultura. Há, porém, uma justificativa para a escolha desses 
temas que é pautada na clareza e na simplicidade da obra literária. Nessa acepção, podemos associar o estabelecimento de temas literários às características dos leitores aos quais se destina a obra. Inevitavelmente, essa correspondência confirma a suposta ideologia já identificada e apontada por Eagleton.

Segundo Bourdieu (2002, p. 69), o estabelecimento de temas facilmente identificáveis permite a indução do erro na concepção daquilo que está sendo proposto e, nesse caso, "a falsa clareza é com frequência obra do discurso do dominante, o discurso daqueles que acham que tudo é óbvio, porque tudo está bem como está". Afirma também em outro estudo que:

Muitas das práticas e das representações [...] não se deixam explicar senão por referência ao campo do poder. [...] o campo do poder é o espaço das relações de força entre agentes ou instituições que têm em comum possuir o capital necessário para ocupar posições dominantes nos diferentes campos (econômico ou cultural especialmente). [...] Ele é o lugar de lutas entre detentores de poderes. (BOURDIEU, 2010, p. 244)

Ora, acreditamos que é por meio da reprodução dessa cultura dominante que a esfera mais ampla e superior da sociedade se garante. Exemplarmente, os projetos políticos pedagógicos elaborados pela escola estão baseados na cultura dominante, se expressam e se corporificam na linguagem dominante e são executados em suas diversas variáveis - incluindo os projetos de leitura -, por meio do código dominante. Nessa esfera, a leitura da obra literária estaria atendendo exclusivamente às demandas curriculares na intenção de legitimar uma organização aceitável a bem da formação do aprendiz leitor. As contribuições teóricas de pensadores da modernidade são necessárias para o esclarecimento dessa relação:

Essa divisão [...] impede uns e outros de colocar adequadamente os problemas mais fundamentais que todas as sociedades colocam, os da lógica específica das estratégias que os grupos, e particularmente as famílias, empregam para se produzir e se reproduzir, isto é, para criar e perpetuar sua unidade, logo, sua existência enquanto grupos, o que quase sempre, e em todas as sociedades, a condição da perpetuação de sua posição no espaço social. (BOURDIEU, 2004, p. 94)

Em termos de redução teórica, podemos inferir, conforme Bourdieu (2004), que esses grupos são na realidade o resultado de um trabalho permanente de manutenção onde o círculo original de representação é a escola. Por essa razão, quando pensamos associar a leitura literária por meio do uso das tecnologias de informação e 
comunicação estamos necessariamente penetrando no domínio curricular onde as representações são, antes de tudo, a possibilidade de cristalização de modelos considerados saudáveis e viáveis para uma sociedade aparentemente bem estruturada.

Numa acepção bem ampla, podemos entender que na esfera de relações inter epistemológicas, subjaz uma discussão sem grandes possibilidades de inferências elucidativas uma vez que há uma enorme abrangência temática pertinente aos campos que permanecem em oposição. Segundo Bhabha (2010), cabe a ambas as áreas de conhecimento analisar tais bipolaridades que constituem os pares organizadores desses conflitos nas ciências humanas e sociais. Nesse sentido, o sociólogo e educador Pedro Demo (2009) numa tentativa de organização de tal bipolaridade comum no domínio da pós-modernidade afirma:

No mundo das tecnologias há euforia e lamento, um jogo entre 'tecnófilos' e 'tecnófobos'. Ambas as posições são inadequadas, porque são acríticas. Não cabe curvar-se ao determinismo tecnológico que resulta em aceitação basbaque, porque nenhum determinismo é real. Nem cabe propalar repulsa obsessiva, porque, sendo o mundo das novas tecnologias naturalmente ambíguo, há, entre tantas dubiedades, também belas promessas. (DEMO, 2009, p. 05)

Segundo Demo, "nem de longe" é possível esclarecer as questões sobre o papel dessas novas tecnologias e o uso das mesmas numa esfera bipolar: tecnófila versus tecnófoba. Uma possibilidade de organização desses pares de oposição seria inevitavelmente arriscada e põe em destaque a ampliação dos espaços de discussão e acesso à obra literária. Nesse sentido, inserir gradualmente as TIC no processo ensinoaprendizagem de Literatura, sem, contudo, suprimir a ideia de Literatura enquanto concepção artística é uma possibilidade tão frágil quanto as ultrapassadas fronteiras que antes separavam os campos de conhecimentos nas humanidades. Porém, essa questão também necessita de outro espaço discursivo para além das usuais fronteiras impostas e ainda resistentes das ciências humanas. Por extensão, tal questão se configuraria também numa nova categoria de análise.

\section{A literatura e as TIC: uma perspectiva pós-moderna}

É natural que se constituam posições extremadas quando se pensa o trabalho docente a partir do uso em sala de aula de novas tendências oriundas das tecnologias de 
comunicação e informação. Quando pensamos a sala de aula em sua forma institucional, de imediato compreendemos se tratar de uma rotina organizada em função de um planejamento que é legitimado pelo currículo, por essa razão, toda e qualquer urgência na modificação dos modelos já estabelecidos e cristalizados podem constituir opiniões severas quando a alteração desses padrões. Assim, a inserção de novos parâmetros tecnológicos provenientes das demandas da sociedade pós-moderna, podem tornar o planejamento didático pedagógico um campo de conflito quando se pretende a execução dessas atuais urgências por meio de práticas antigas.

Falamos da Literatura em sala de aula, ou mais especificamente da leitura literária. Pesquisas recentes apontam para uma abordagem que vincula a sucessão de aparatos tecnológicos desenvolvidos na nossa época à prática da leitura. Porém, se observamos a história do sujeito leitor, veremos que a prática da leitura é anterior à descoberta de determinados softwares, hardwares e aplicativos que se ajustam perfeitamente à prática docente. Rejeitar a relação existente entre as novas tecnologias e o processo ensino aprendizagem, é recusar, por extensão, a nova configuração do mundo moderno.

Segundo Pinheiro-Mariz e Silva (2012, p. 02), essa relação entre a educação e as tendências tecnológicas ocorreu "pelo fato de que nos dias de hoje não se pode pensar em educação sem a sua relação direta com os recursos oferecidos pelas tecnologias atuais [...] e essa é uma realidade que abraça a maioria das crianças". Observamos que segundo as afirmações apontadas pela autora, não há como desvincular o uso dessas tecnologias no dia-a-dia da realidade educacional. Ainda que haja resistências por parte de alguns professores que insistem em manter um posicionamento de recusa e radicalismo acerca da inserção da tecnologia na sala de aula, é improvável que esses aprendizes da era da informação, permaneçam indiferentes à esse novo formato da sociedade na modernidade tardia.

Ora, se pensarmos que diversas tecnologias que foram desenvolvidas visando o processo ensino aprendizagem já se sedimentaram nas práticas educacionais das nossas escolas de educação básica, e, por extensão em todas as modalidades de ensino, não há como suprimir o papel do mercado de consumo nessa esfera. Ou seja, ainda que o aluno não disponha de um notebook em sala de aula, ele terá um computador em casa ou mesmo no laboratório de informática da escola para o uso em pesquisas e demais relações sociais. Suprimimos nessa esteira, a posse de celulares com acesso à internet como iPad's, iPhone's e demais dispositivos que compõem essa imensa lista de 
componentes que já estão atrelados à rotina dos indivíduos socialmente conectados ao mundo virtual e, com níveis econômicos distintos, portanto.

Por essa razão, e conforme assevera Pinheiro-Mariz e Silva (op. cit., p. 02), observamos que "hoje já não é mais possível se propor um ensino, [...] sem que ferramentas tecnológicas como o uso do computador estejam presentes, haja vista a acessibilidade a esse recurso tanto nas escolas, quanto no uso doméstico". Isso explica o definitivo redimensionamento da disciplina de informática no currículo da educação básica. Isto é, as atuais pesquisas apontaram para uma visão ultrapassada a respeito da aprendizagem da informática na escola, e concluíram que tal concepção prescinde de um aspecto formal para sua aplicabilidade na vida do sujeito.

Essa digressão que relaciona as TIC à leitura literária é necessária para consolidar a relação de aproximação e distanciamento entre o uso das tecnologias de informação e comunicação e o ensino aprendizagem de Literatura é a possibilidade de associar numa mesma esfera de intencionalidade, campos de conhecimentos tão distintos. Por essa razão, ressalvamos as contribuições de autores como Colomer (2010) que direciona suas teorizações na formação de aprendizes leitores como cidadãos da cultura escrita. Nessa acepção, tal formação ainda é um dos principais objetivos educativos da escola, não obstante o papel das tecnologias.

Dessa forma, podemos inferir que dentro desse propósito geral, a finalidade da educação literária pode ser resumida como um processo essencialmente formativo no que se refere ao leitor competente. A Literatura necessita de um espaço permanente para o debate em busca de novos olhares ou de um enfoque que privilegie o corpo discente. Nesse sentido, há uma extensa discussão a respeito da Literatura na escola, e ainda o estabelecimento de um estudo descritivo sobre: texto literário especificamente no tocante ao uso das tecnologias de informação e comunicação que se pode utilizar no ambiente heterogêneo da sala de aula. Nessa perspectiva, ainda persiste uma complexa relação entre a leitura da obra literária e as novas demandas advindas de concepções pós modernas que atribuem ao aluno um novo universo acadêmico: o uso das tecnologias de informação e comunicação no processo ensino-aprendizagem.

Não há como suprimir nesse contexto que os mecanismos mais usuais de produção editorial e de consumo permitiram que a Literatura ganhasse um novo fluxo de circulação e multiplicação nesse quadro permanente de sucessivas alternâncias de bens de consumo. Isto vale para a orientação muito usual que cerca a possibilidade de downloads de algumas obras literárias que podem e devem ser consumidas - numa 
acepção do mercado - por qualquer indivíduo em qualquer lugar onde seja possível o acesso a esses novos dispositivos tecnológicos. Nesse esquema ideológico de circulação da obra literária, Colomer (2007) aponta o seguinte:

\begin{abstract}
Os mecanismos modernos de produção editorial e consumo multiplicaram os livros; a internacionalização do mercado e a cultura os difundiu de maneira distinta e a evolução das tendências artísticas em direção ao jogo intertextual completou um panorama configurado agora por uma grande quantidade de obras, que aparecem em um mesmo momento em muitos lugares, em diferentes idiomas e que se escrevem e leem no contexto de sistemas artísticos e ficcionais muito inter-relacionados. (COLOMER, 2007, p. 23)
\end{abstract}

A partir do que assevera Colomer (2007) e excetuando os conceitos de desajustamentos propostos pela autora, podemos inferir que essa nova configuração que ora se apresenta na modernidade tardia, permitindo com que as obras literárias circulem em diferentes espaços, aponta para um novo problema. Ou seja, observa-se mais recentemente que esse fenômeno logístico de acesso à Literatura destituiu a ultrapassada função da escola que era transmitir a cultura literária.

Por essa razão, é possível, assegurar o ensino de Literatura ou, mais especificamente, a leitura literária por meio das tecnologias de informação e comunicação a partir da utilização de recursos adequados aos objetivos propostos pelos docentes em seus planejamentos. Para efeito didático, sugerimos nesse contexto alguns sites já consolidados nas práticas de leitura literária e que podem dentro de uma organização disciplinar contribuir para o desenvolvimento e formação do leitor literário.

São eles: http://www.lerlivrosonline.org

http://www.livroson.com

http://www.e-livros.clube-de-leituras.pt

http://www.livroseafins.com

Observamos que os conteúdos dos sites acima relacionados são referenciados e constituem um material de apoio às atividades de leitura literária em sala de aula. Vale destacar, porém, que, não obstante o conteúdo dos sites a que nos referimos servir para atividades de leitura fruitiva podem, entretanto, ser adequadas para fins didáticos e promover o ensino de Literatura.

\title{
5. Conclusão
}


As questões referentes ao currículo suscitam inúmeras ideias e, estas estão sempre associadas às distintas concepções, das quais decorre a variedade de formas pelas quais a educação é concebida historicamente. Segundo Goodson, "no novo futuro social, devemos esperar que o currículo prescritivo se comprometa com as missões, paixões, e propósitos que as pessoas articulam em suas vidas”. (2007, p. 251). Nesse sentido, compreendemos que todas as discussões e tentativas sistemáticas em busca da inserção integral do uso das tecnologias de informação e comunicação nas demais áreas de formação, passam, necessariamente, pelo domínio do currículo.

E, para além dessas concepções, há ainda uma multiplicidade de inferências teóricas que dificultam a compreensão sobre o currículo. Associar a ideia de currículo ao conceito de tecnologias modernas e seu uso em aulas de Literatura, é, sobretudo, uma tarefa complexa da qual só podemos nos ocupar no campo livre do discurso acadêmico, ainda que as tecnologias de informação e comunicação exijam um olhar menos discursivo e mais prático. Porém, essa também é outra discussão.

Dentre os atuais pares organizadores dos conflitos nas ciências sociais propostos por Canclini (2008) tradição/modernidade, local/global, norte/sul, podemos, a partir dos recentes estudos culturais, incluir outros pares de oposições: latinoamericano/europeu, lugar/não-lugar e erudito/popular. Possivelmente, na tentativa de argumentar que o mundo moderno e suas paisagens transitórias plasmam em formas.

Nessa perspectiva, as ideias de pensadores da modernidade podem elencar outras discussões necessárias aos debates sobre o modo como as ciências humanas e sociais olham para o homem na modernidade tardia quando do uso das tecnologias de informação e comunicação. Vale ressaltar, porém que as ciências humanas e sociais talvez não sejam capazes de juntar numa mesma esfera de julgamento o homem e suas concepções subjetivas. Pois, numa acepção moderna e ambígua o homem vai sempre permanecer como objeto e sujeito de todas as categorias de análise das pesquisas nas áreas das humanidades.

Pensar a inserção das tecnologias de informação e comunicação para o ensino de Literatura corresponde ao atendimento de uma nova demanda do próprio homem moderno. As descobertas tecnológicas com todas as novas abordagens que decorrem de seu amplo uso, podem promover para além da inclusão do sujeito na esfera do mundo informatizado, uma nova concepção acerca do processo ensino aprendizagem que pode fazer uso dessas tecnologias para garantir o desenvolvimento global desse homem que está definitivamente inserido no mundo moderno. 


\section{Referências}

ALMEIDA, Marco. Ciência da informação e Literatura. $1^{\mathrm{a}}$ ed. Campinas: Editora Alínea, 2012.

BHABHA, Homi. O local da cultura. $5^{\text {a }}$ ed. Belo Horizonte: Editora UFMG. 2010.

BOURDIEU, Pierre. As regras da arte: gênese e estrutura do campo literário. $2^{\mathrm{a}}$ ed. São Paulo: Companhia das Letras, 1996.

BOURDIEU, Pierre. O poder simbólico. $14^{\mathrm{a}}$ ed. Rio de Janeiro: Bertrand Brasil, 1910.

COLOMER, Teresa. Andar entre Livros. $1^{\mathrm{a}}$ ed. Global Editora: São Paulo. 2009.

COLOMER, Teresa. Formação do Leitor Literário. $1^{\mathrm{a}}$ ed. Global Editora: São Paulo. 2010.

DEMO, Pedro. Tecnofilia \& tecnofobia. B. Téc. SENAC: a R. Educ. Prof., Rio de Janeiro, v. 35, n. 1, jan./abr. 2009.

EAGLETON, Terry. Teoria da literatura: uma introdução. Trad. Waltensir Dutra. São Paulo: Martins Fontes, 1994.

EAGLETON, Terry. Marxismo e crítica literária. $1^{a}$ ed. São Paulo: Unesp, 2011.

EAGLETON, Terry. A ideia de cultura. $1^{\mathrm{a}}$ ed. São Paulo: Unesp, 2005.

GOODSON, Ivor. Currículo, narrativa e o futuro social. Revista Brasileira de Educação. $1^{\text {a }}$ ed. V. 12, no 35. maio/agosto. 2007.

PINHEIRO-MARIZ, J.; SILVA, M. R. S. A tecnologia de informação e comunicação na didática do ensino do francês língua estrangeira para crianças. Revista Científica Digital da FAETEC, v. 4, p. 3-18. Rio de Janeiro, 2012.

RANGEL, Egon. Letramento literário e livro didático de língua portuguesa: os amores difíceis. In: Literatura e letramento: espaços, suportes e interfaces - o jogo do livro. (Org) Aparecida Paiva. Belo Horizonte: Autêntica, 2003.

SILVA, Tomaz Tadeu. Documentos de Identidade: uma introdução às teorias do currículo. 2aed. Autêntica: São Paulo. 1999. 